Ano 6, Vol. 6 (1), nº 1. 2021, janeiro/julho de 2021.

\title{
Diálogos intersemióticos entre Jorge de Lima e Murilo Mendes
}

José Antonio Santos de Oliveira, Universidade Estadual de Alagoas; E-mail: jaletras1997@gmail.com

RESUMO - Este artigo é oriundo de um Projeto de Iniciação Científica, o qual promoveu uma exegese do livro de fotomontagens do escritor alagoano Jorge de Lima, intitulado A pintura em Pânico, produzido entre 1938 a 1940 e publicado em 1943. Abordando como o autor conseguiu extrair poesia dessa técnica vanguardista para o cenário cultural da época. Ademais, esta obra foi pouco estudada pela crítica literária e, por conseguinte, buscou-se investigar as fotomontagens, de modo a emergir leituras inovadoras sobre este corpus. Nesse sentido, a análise partiu da premissa do caráter dialógico da literatura, pois o livro enfatizado foi analisado de maneira comparativa, cuja discussão, alicerçada na Tradução Intersemiótica, verificou como a literatura é ressinificada no contato com outros sistemas semióticos (fotografia/pintura). Dessa forma, A pintura em pânico recupera o diálogo com outras obras e este contato se manifesta nas fotomontagens limianas, quando o poeta/artística constrói sua obra a partir de traduções/ metamorfoses do livro A poesia em pânico, de Murilo Mendes, trazendo para produção tanto o religioso, quanto o caos e o medo no plano onírico, estes oriundos do surrealismo. Portanto, esta pesquisa mostrou-se embasada nos postulados teóricos de Plaza (2003).

Palavras-Chave: Tradução intersemiótica. A pintura em pânico. Jorge de Lima.

\begin{abstract}
This article comes from a Scientific Initiation Project, which promoted an exegesis of the photomontages book by Alagoas writer Jorge de Lima, entitled A Pintura em Pânico, produced between 1938 and 1940 and published in 1943. Addressing how the author managed to extract poetry of this avant-garde technique for the cultural scene of the time. In addition, this work has been little studied by literary criticism and, therefore, it has sought to investigate photomontages, in order to emerge innovative readings on this corpus. In this sense, the analysis started from the premise of the dialogical character of literature, since the emphasized book was analyzed in a comparative way, whose discussion, based on Intersemiotic Translation, verified how literature is resinified in contact with other semiotic systems (photography / painting). In this way, Panic painting recovers the dialogue with other works and this contact is manifested in the boundary photomontages, when the poet / artist builds his work from translations / metamorphoses of the book A poetry in panic, by Murilo Mendes, bringing to production both the religious, as well as the chaos and fear in the dream plane, these coming from surrealism. Therefore, this research proved to be based on Plaza's theoretical postulates (2003).
\end{abstract}

Keywords: Intersemiotic translation. Panic painting. Jorge de Lima. 


\section{Introdução}

O presente artigo concentra algumas reflexões e resultados do projeto sobre a poética de Jorge de Lima em suas fotomontagens, utilizando as contribuições da análise comparativa proposta pelo viés teórico da Tradução Intersemiótica. A intersemiose, que, por sua vez, faz parte dos três pilares do grupo de pesquisa: Literatura, Intersemiose e Cultura (GELIC), é usada para pensar uma obra, de certa forma, desconhecida de Jorge de Lima, se equiparada ao "Poemas Negros" (1947) e "Inversão de Orfeu" (1952), por exemplo.

Ressalta-se, nesse sentido, a importância de estudar a literatura alagoana, como ela se configura no cenário da literatura brasileira, e Jorge de Lima, considerado por alguns críticos como um dos maiores representantes desta literatura no Brasil ao lado de Manuel Bandeira e Carlos Drummond de Andrade. O que causa estranheza, contudo, é que na contramão a esses autores mencionados, o poeta alagoano está longe de ser problematizado da maneira que merece pela crítica, se levar em consideração a dimensão e complexidade de suas obras.

Nesse sentido, o trabalho experimental de Jorge de Lima ainda na primeira metade do século XX mostra-se imiscuído às poesias murilianas e a outras formas de arte (Cinema surrealista), existentes nesse período de produção. Todavia, comumente, são trabalhadas de modo avulso e, por esse motivo, a ponte dialógica é deixada de lado, desperdiçando o ensejo de construir leituras inovadoras pela comparação, ao mesmo tempo em que a crítica ainda não havia averiguado os aspectos submersos e relevantes das fotomontagens, uma vez que os trabalhos científicos identificados teciam comentários genéricos, de certa forma, desprovidos de proficuidade analítica.

É pensando nessas reflexões, que esta pesquisa buscou esmiuçar os pormenores dessa forma de arte trabalhada com esmero, por Jorge de Lima, embora, pareçam estranhas à primeira vista. "A princípio as criações nascem bisonhas, mecânicas e mal inventadas. Mas aos poucos o espírito começa a trabalhar com mais facilidade". (ANDRADE, 1939). De fato, o primeiro contato com as fotomontagens limianas configura-se estarrecedor e inquietante, porque são formadas a partir de figuras desconexas com traços surrealistas, o que não impossibilita, mas antes realça, a diversidade de construções imagéticas e possíveis leituras sobre as imagens justapostas, cujo resultado é uma produção poética, repleta de analogias, princípio básico da linguagem poética assim como aborda Cândido (1996), com traços das fases pelas quais Jorge 
de Lima perpassou, isto é, A pintura em pânico carrega consigo o discurso religioso da trilogia cristã do poeta coadunado às perspectivas políticas, introspectivas e sociais do agora artista plástico, o que condiciona o hermetismo de suas fotomontagens, ao passo que expõe o caráter multifacetado de suas produções plásticas e literárias.

Para embasar as leituras de como Jorge de Lima traduz todas essas formas/vozes em suas fotomontagens, recorreu-se também às explicações sobre polifonia e dialogismo propostas por Mikhail Bakhtin, uma vez que as expressões artísticas recuperam outras obras no seu passado numa espécie de jogo dialógico, além de conter, em seus cernes, várias vozes, a fim de construírem sentidos inusitados. Nesse aspecto em especial, percebeu-se e trabalhou-se também junto ao conceito de poética sincrônica defendido por Júlio Plaza (2003), que é justamente essa tradução do passado convergindo no presente, momento de produção de uma obra, granjeando sentidos específicos ao possibilitar a tradução das formas na arte.

\section{Leitura Intersemiótica de "A pintura em pânico"}

Devido à falta de análises sistemáticas sobre o livro de fotomontagens limiano, percebese que estas perspectivas se mostram, de certa forma, pioneiras, tendo em vista que se busca discutir sobre as imagens e como elas dialogam com outros sistemas semióticos. Nessa perspectiva, as fotomontagens de Jorge de Lima criam imagens poéticas pelo atrelamento de figuras opostas, o interessante é que essa construção imagética parte da premissa religiosa cristã, assim como Anunciação e encontro de Mira-Celi, mas ao mesmo tempo, estabelece contato com um certo paganismo e elementos da mitologia, levando em consideração, que, no período de produção, o autor se utilizava de revistas com os mais variados temas, para reorganizá-las nas fotomontagens.

Além disso, verifica-se duas formas inovadoras em sua poesia nas fotomontagens, a primeira é fruto do desejo de renovação estética de Lima, já que ele mesmo afirma não gostar de se repetir no que fazia; a segunda nasce das vicissitudes em relação A pintura em pânico com os outros livros cheios de referências cristãs, basta recordar que nos livros mencionados, sua metalinguagem ensaiava uma perspectiva diferenciada de poesia e almejava o resgate dos ideias cristãos para literatura (BOSI, 2015), o que não acontece nas fotomontagens, nestas, vêse o uso do cristianismo para refletir sobre aspectos sociais existentes no século $\mathrm{XX}$, a exemplo 
da fotomontagem que problematiza os efeitos nefastos da segunda guerra mundial no ser humano a partir da relação analógica com a celebração da missa. Assim sendo, continua o religioso místico, mas outras vozes juntam-se, a fim de formarem imagens, que levam o sujeito que contempla a uma espécie de epifania, afinal, a poesia, como arte sublime do ser, consegue produzir esse efeito com maestria.

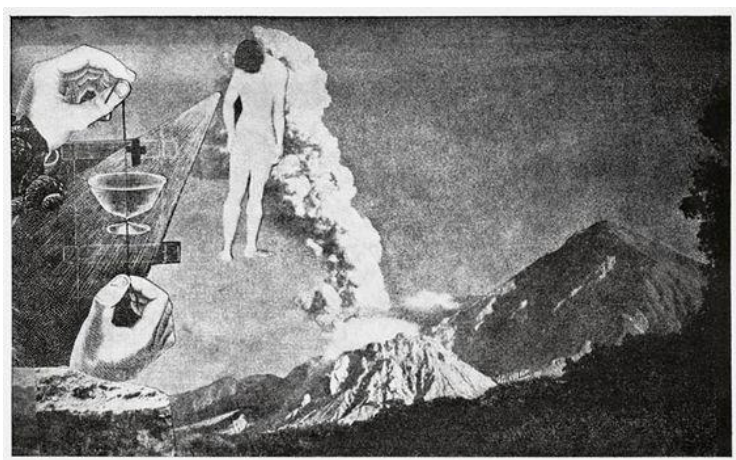

Figura 1: A ideia fixa

De acordo com Eisenstein (2002, p. 51), a respeito da colagem de imagens para produção de sentidos, fala sobre o objetivo da montagem "[...] a justaposição destes precisos elementos e não de elementos alternativos- suscite na percepção do telespectador a mais completa imagem desse tema preciso". Traduzindo esse pensamento para respaldar as reflexões sobre a fotomontagem revelada acima, é possível observar como Jorge de Lima se utiliza de elementos assertivos, justamente pelo caráter analógico das duas partes amalgamadas na obra, cuja semelhança agrega e potencializa os sentidos desejados.

$\mathrm{Na}$ fotomontagem, veem-se as mãos do sacerdote segurando o cálice, aparentemente celebrando a santa missa, e mais distante, os montes e uma fumaça elevando-se ao céu, ao mesmo tempo em que a luz do cálice em forma de caminho toca o céu. Sabe-se que a missa representa o sacrifício de Cristo e, para os católicos, renova-se a cada dia, tal sacrifício é oferecido a Deus pela salvação de todos os pecadores. No entanto, a missa na obra se completa no contato com a outra imagem transposta, colada por Jorge de Lima. Tanto é que o ponto de ligação entre o rito católico e os aspectos sociais é a fumaça. A fumaça das bombas, das violências, e da guerra encontra-se nos montes, sendo metaforizada e coadunada a ideia do incenso - este é usado na missa para representar as orações dos fiéis, que são levadas até Deus 
no céu. Nesse contexto, Jorge de Lima atrela o sacrifício de Cristo ao sofrimento dos homens, como se fossem elevados aos céus em orações de súplicas pelo momento tenebroso pelo qual o mundo passava. Nesse sentido, tem-se a concatenação da religiosidade limiana à sensibilidade do poeta frente ao mundo, aos efeitos nefastos da guerra.

Além disso, o ser mutilado, que timidamente paira na trilogia cristã, emerge com desassombro em A pintura em pânico, tal mutilação reverbera a fragmentação do sujeito diante do seu caos individual, sem esquecer as pessoas esmiuçadas fisicamente/psicologicamente durante as guerras do século XX. Somando-se a isto, depreende-se como Jorge de Lima e Murilo Mendes dialogam sistematicamente em suas produções, sobretudo, pelo caos e pelo religioso, o que parece, afinal, é que estas duas idiossincrasias de A pintura em Pânico e $A$ poesia em pânico mostram-se concatenadas de maneira íntima, provando como o discurso religioso fundamenta, em parte, o medo do sujeito, isto é: o medo da morte, o medo do pecado, o medo da condenação eterna. Para justificar esse pensamento, basta observar a seguinte fotomontagem e, em seguida, compará-la ao poema $O$ impertinente, de Murilo Mendes.

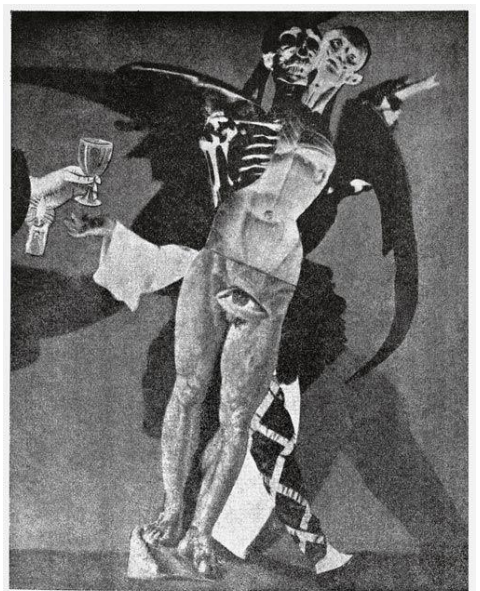

Figura 2: Eis o cálice do fel

Esta fotomontagem, por exemplo, é intrigante e conversa poeticamente com os textos produzidos por Murilo Mendes, porque este também fusiona nos versos o homem e a religião. No texto Poema visto por fora, inserido em Poesia em pânico, a matéria da poesia se confunde com os ritos religiosos e o corpo-poema é a própria celebração do homem como parte de Deus. A fotomontagem apresentada pela figura 2 carrega a túnica do discurso religioso traduzido na 
imagem pela figura do cálice, que estabelece com os outros elementos do texto o sentido do caos. Podem-se perceber os opostos construindo sentidos imagéticos, cuja tensão é a principal propagadora de efeitos sugestivos. Dessa forma, a imagem do sacerdote em total congruência com a legenda, que pelo jogo com as palavras, faz referência a santa missa, mesmo que a palavra fé tenha sido substituída pelo termo fel, que situa o leitor frente ao gosto amargo de pagar pelos pecados e que possibilita a construção da ideia de condenação, uma vez que o cálice com o de sangue de Cristo está sendo entregue a uma alma, possivelmente, já condenada e abraçada pela morte, representada pelo ser obscuro atrás.

Além disso, de costas ao sacramento da comunhão, por traz das figuras centrais, encontra-se um homem de cabeça baixa, aparentemente sofrendo pelos seus delitos, que são transmitidos pela cara de pânico do sujeito, perdido pelos seus pecados. É possível que o que tenha levado a construção dessa fotomontagem seja a percepção limiana frente aos desregramentos da sexualidade em meio à dicotomia: bem e mal, uma vez que o olho está localizado na genitália do homem, assim como em outra fotomontagem, pelas formas do corpo, verificava-se um olho também na vagina de uma mulher ao lado dos personagens bíblicos Caim e Abel.

Nesse sentido, infere-se o ser humano mesmo querendo agradar a Deus, vivendo sua doutrina, apresenta uma certa tendência a se entregar aos seus desejos e, por isso, vive seus impulsos, sendo conduzido a obscuridade do inferno, este figurativo, ao trazer no cerne da mensagem a perspectiva do interdito, situando mais uma vez o pânico. Dessa forma, a religião fornece subsídios para a formação do medo do eu lírico, o seu conhecimento acerca da doutrina o leva ao conflito interno entre o gozo e a pureza, entre sua salvação e a factível condenação eterna.

Essa situação conflituosa entre o profano e o sagrado, entre o pecador e a remissão também é visualizada com expressividade em "A poesia em pânico", da autoria de Murilo Mendes, cujo estreitamento temático já se evidencia no título do livro, ou seja, Jorge de Lima pensa o pânico na fotomontagem, traduzindo a essência conflituosa do autor mineiro para suas pinturas/fotografias. Plaza (2003, p.1), ao refletir sobre a construção dialógica das obras, explica que "só é possível compreender o presente na medida em que se conhece o passado. Esta é uma condição aplicada a quase todas as situações que envolvem o ser humano". Por essa razão, para compreender as fotomontagens do artista alagoano, traz-se também um poema de Murilo, que conversa demasiado com “A pintura em pânico". 
O poema "O impertinente" do Murilo sintetiza a ideia da fotomontagem limiana, marcado pelo sofrimento religioso do eu lírico diante dos seus pecados, ele assume uma postura surrealista ao transmitir a disparidade entre uma vida de intimidade com Deus e a vida de entrega aos prazeres da carne, essa dicotomia, por sua vez, se embasa, assim como a fotomontagem, na inutilidade do sacramento da comunhão em relação ao peso dos pecados hereditariamente sentido pelo eu lírico. O recurso estético promovido pela pontuação estabelece uma visão pessimista do eu frente ao mundo, demonstrando de um lado a solidão, de outro a abnegação da fé religiosa, por causa da própria solidão humana.

Em ambos os textos, fotomontagem e poema, os elementos-símbolos do cristianismo apontam para a inversão de valores, no primeiro caso pela palavra "fel" e no segundo pela recusa da comunhão. A ironia sugerida nos textos coloca em tensão o diálogo com a religião.

Desse modo, a imagem assustadora do pecado para o cristianismo é recuperada nos poemas pelo recurso estético do discurso ambíguo que mostra simultaneamente a ótica da punição centrada no discurso religioso e a ótica da punição centrada na crise do próprio sujeito dividido entre desejo e impedimento.

Nesse ponto, as duas formas de arte problematizam o liame entre homem e religião, sugerindo a condenação dos indivíduos, que não puderam conter seus impulsos e/ou mostraramse impertinentes, ou seja, não fizeram mortificações e boas obras suficientes, a fim de angariar a salvação. Perspectiva que vai aparecer também no poema "O mau samaritano", de A Poesia em pânico, no qual o eu lírico evidenciará poeticamente a sua angústia por não praticar as obras de amor ao próximo ensinadas por cristo, mantendo diálogo religioso com a bíblia.

\section{O IMPERTINENTE}

Quem me consolará no mundo vão?

Homens, tenho convosco relação da forma

Nuvem sólida, rosa virginal, água branca

E tu, antiga sinfonia aérea

Pertenceis ao anjo, não a mim.

Eu digo ao pecado: tu és meu pai.

Eu digo à podridão: tu és minha irmã.

A presença real do demônio

É meu pão cotidiano:

Minha alma comprime a aleluia gloriosa. 
Ano 6, Vol. 6 (1), no 1. 2021, janeiro/julho de 2021.

\author{
Hóstias puras \\ Inutilmente vos entregueis a mim.
}

Sendo assim, observa-se o mesmo o assunto pensado por enquadres semióticos diferentes, complementando-se, cuja ideia se acentua nos pormenores construídos nas duas formas de arte apresentadas nesse momento da discursão e, nessa perspectiva, pode-se afirmar, que o medo em ambas as obras é consequência da religiosidade dos escritores, embora, diante dos acontecimentos que perpassavam a produção das fotomontagens durante 1938 a 1940, Jorge de Lima não se restrinja ao conflito introspectivo de um eu lírico, pelo contrário, as fotomontagens problematizavam os acontecimentos que inquietavam o poeta, sejam os pessoais ou os presentes nas diversas realidades sócio-político e, até mesmo, culturais de sua época.

Desse modo, sabe-se que as fotomontagens nascem desses períodos conflituosos e em sua própria construção já se evidencia a forma como o autor enxergava o momento presente e a maneira pela qual se via diante de si e do mundo: mutilado. A composição estrutural da colagem nas fotomontagens, nesse caso, aponta para o mundo desfigurado e desconstituído de uniformidade e paz. Eisenstein (2002) ratifica, ao comentar que as fotomontagens emergem em momentos de instabilidade social e individual do ser. Processo semelhante acontece nas composições poéticas comuns em forma de poema, nestas, percebe-se como o contexto histórico influencia na liberdade dos versos ou, em sociedades mais rígidas, observa-se a metrificação acentuada, justamente porque a estrutura da literatura, música e das artes em perspectiva macroestrutural, por assim dizer, refletem em si, a estrutura comportamental do ser humano na sociedade. Portanto, é necessário pensar a forma amalgamada ao social, pois, se a análise das fotomontagens se limita aos dois aspectos de modo isolado, os resultados serão imprecisos e facilmente refutáveis.

\title{
Considerações Finais
}

Percebe-se, portanto, que analisar "A pintura em pânico", desprezando os elementos subjacentes de sua produção, pode acarretar leituras errôneas, ou melhor, incompletas, porque a técnica da fotomontagem permite essa ligação de imagens, sentidos e figuras de modo expressivo, sobretudo, em seu momento de feitura, quando o artista recorta figuras de livros e revistas e reagrupa-as com o intuito de gerar efeito estético. 
Ano 6, Vol. 6 (1), no 1. 2021, janeiro/julho de 2021.

É por essa razão, que se observa uma diversidade de interpretações factíveis para as fotomontagens do livro, cada qual remetendo e complementando as faces imagéticas de Jorge de Lima. Afinal, em uma fotomontagem, por exemplo, pode-se ver o diálogo profícuo com os poemas de Murilo Mendes, o discurso religioso como ferramenta de sentido e, além de tudo isso, o caos e a melancolia, oriundos desses fatores elencados. Primeiro, porque é em Murilo Mendes, mesmo na sua fase católica, que já acentua o seu apego ao caos e inquietações referentes ao pecado e, em segundo plano, porque a organização da fotografia limiana compartilha desses aspectos por meio da tradução, em outras palavras, tem-se outro sistema semiótico (fotomontagem), mas que pensa, dialoga, traduz os sentidos descritos pelo autor de A poesia em pânico.

Dessa forma, A tradução intersemiótica "consiste na interpretação dos signos verbais por meio de sistemas de signos não-verbais", ou "de um sistema de signos para outro". (JAKOBSON, 2007, p.65 e 71). Nesse caso, Jorge de Lima interpreta e traduz a poesia muriliana para fotomontagem, adaptando elementos que convergem entre si, conforme já discutido. 


\section{Referências Bibliográficas}

ANDRADE, Mário de. "Fantasias de um Poeta". In: PAULINO, Ana Maria (org.) O Poeta Insólito: fotomontagens de Jorge de Lima. São Paulo: IEB/USP, 1987.

BAKHTIN, Mikhail. Questões de literatura e de estética: a teoria do romance. Aurora F. Bernardini (tradução). São Paulo: Hucitec, 2002.

BATAILLE, Georges. O erotismo. Tradução de Fernando Scheibe. Belo Horizonte: Autêntica Editora, 2014.

BAZIN, André. "Pintura e cinema." In: O cinema: ensaios. Tradução deEloisa de Araújo Ribeiro. São Paulo: Brasiliense, 1991.

BOSI, Alfredo. História concisa da literatura brasileira. São Paulo: Cultrix, 2006.

BRETON, André. Manifestos do Surrealismo. Tradução de Sérgio Pachá. Rio de Janeiro: Nau Editora, 2001.

CANDIDO, Antonio. "Surrealismo no Brasil". In: Brigada ligeira e outros estudos. São Paulo: Editora UNESP, 1992.

CAÑIZAL, Eduardo Peñuela. "Surrealismo". In: MASCARELLO, Fernando (org.). História do cinema mundial. São Paulo: Papirus, 2006.

Dali: grandes mestres. Abril coleções, volume 6. São Paulo: Editora Abril, 2011.

EISENSTEIN, Sergei. O sentido do filme. Tradução de Teresa Ottoni. Rio de Janeiro: Zahar, 2002.

JAKOBSON, Roman. "Aspectos linguísticos da tradução”. In: Linguística e comunicação. Tradução de Izidoro Blikstein e José Paulo Paes. São Paulo: Cultrix, 2007.

KRISTEVA, Julia. Introdução à semanálise. Lúcia Helena França Ferraz (tradução). São Paulo : Perspectiva, 2005.

LIMA, Jorge de. "Anunciação e encontro em Mira-Celi." In. Poesias completas. Volume II (Coleção Poiesis). Rio de Janeiro: Nova Fronteira, 1980.

LIMA, Jorge de. A pintura em pânico. Rio de Janeiro: Tipografia Luso-Brasileira, 1943.

MENDES, Murilo. "Poesia em pânico." In: PICCHIO, Luciana Stegagno (ORG.). Poesia completa e prosa. Rio de Janeiro: Nova Aguilar, 1995.

MÜLLER, Adalberto. Linhas imaginárias: poesia, mídia e cinema. Porto Alegre: Sulina, 2012.

PAES, José Paulo. "O surrealismo na literatura brasileira”. In: Gregos e Baianos. São Paulo: Brasiliense, 1985.

PLAZA, Julio. Tradução Intersemiótica. São Paulo: Perspectiva, 2003. 